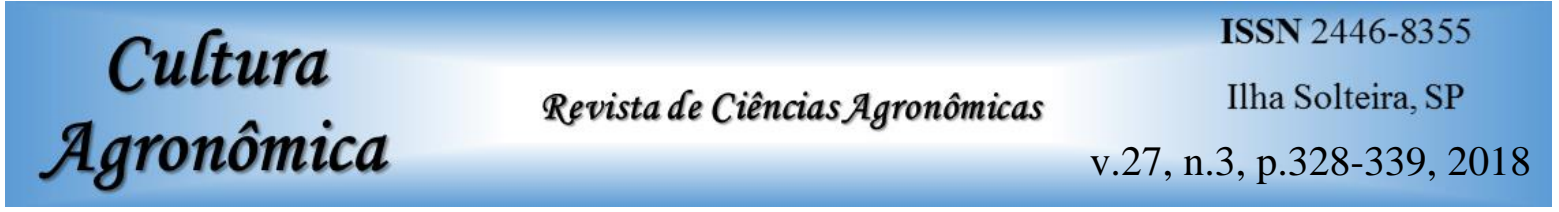

\title{
MULTIPLICAÇÃO E ENRAIZAMENTO IN VITRO DA AMOREIRA PRETA CV. XAVANTE
}

\author{
Jacks Anderson de Toledo ${ }^{1 *}$, Luiz Antonio Biasi ${ }^{2}$ \\ ${ }^{1}$ Graduando em Agronomia, Universidade Federal do Paraná (UFPR), Setor de Ciências Agrárias, Curitiba, \\ PR. *E-mail: toledojks@gmail.com \\ ${ }^{2}$ Professor Titular, Universidade Federal do Paraná (UFPR), Departamento de Fitotecnia e Fitossanitarismo, \\ Setor de Ciências Agrárias, Curitiba, PR.
}

Recebido: 19/01/2018; Aceito: 06/06/2018

RESUMO: O presente trabalho teve por objetivo avaliar o efeito da 6-benzilaminopurina (BAP) na multiplicação de brotações e de diferentes meios de cultura no enraizamento in vitro da amoreira-preta cv. Xavante. O primeiro experimento foi constituído por três concentrações de BAP $(0,1$ e $5 \mu \mathrm{M})$ em meio de cultura MS. O segundo experimento foi constituído pelo cultivo em meio de cultura com BAP $(0,10$ e $20 \mu \mathrm{M})$ por 7 dias, com posterior transferência para meio de cultura isento de reguladores por mais 28 dias. Para o enraizamento in vitro testaram-se quatro meios de cultura (meio MS semissólido; meio MS semissólido com adição de carvão ativado; meio MS líquido com adição de vermiculita; e meio MS líquido com adição de blocos de espuma fenólica). As plantas dos tratamentos de enraizamento in vitro foram submetidas a aclimatização. Concluiu-se que a adição de $5 \mu \mathrm{M}$ BAP ao meio de cultura MS é eficaz na multiplicação de brotações da amoreira preta cv. Xavante. Para o enraizamento in vitro recomenda-se o meio de cultura MS líquido com vermiculita. As plantas de amoreira preta cv. Xavante apresentam facilidade para o enraizamento e aclimatização.

Palavras-chave: Rubus sp. Micropropagação. Pequenas frutas.

\section{MULTIPLICATION AND IN VITRO ROOTING OF BLACKBERRY CV. XAVANTE}

\begin{abstract}
The objective of the present work was to evaluate the effect of 6benzylaminopurine (BAP) on the multiplication of shoots and different culture media in in vitro rooting of blackberry $\mathrm{cv}$. Xavante. The first experiment consisted of three concentrations of BAP $(0,1$ and $5 \mu \mathrm{M})$ in MS culture medium. The second experiment consisted of cultivation in culture medium with $\operatorname{BAP}(0,10$ and $20 \mu \mathrm{M})$ for 7 days, and after transfer to MS culture medium without growth regulators for more 28 days. For in vitro rooting four culture media (semi-solid MS medium, semi-solid MS medium with addition of activated carbon, liquid MS medium with addition of vermiculite, and liquid MS medium with addition of phenolic foam blocks). Plants of in vitro rooting treatments were submitted to acclimatization. It was concluded that the addition $5 \mu \mathrm{M}$ of BAP to the MS culture medium is effective in the shoot multiplication of blackberry cv. Xavante. In vitro rooting
\end{abstract}


using liquid MS culture medium with vermiculite is recommended. Plants of blackberry cv. Xavante are easy to root and acclimatization.

Key words: Rubus sp. Micropropagation. Small fruits.

\section{INTRODUÇÃO}

A amora preta é uma fruta rica em substâncias nutracêuticas, principalmente de origem fenólica, como flavonoides e antocianinas, que apresentam grande capacidade de reagir com radicais livres que causam estresse oxidativo, contribuindo para a prevenção de diversas doenças (FERREIRA et al., 2010; GUEDES et al., 2014). Ela encontra-se em expansão no Brasil com destacado crescimento em regiões subtropicais e tropicais, permitindo a obtenção de elevadas produtividades nos primeiros anos após a implantação dos pomares (PIO e GONÇALVES, 2014; CURI et al., 2015). A cultivar Xavante produziu 5 t.ha $^{-1}$ no segundo ano após o plantio quando cultivada em Cerro Azul, PR, que possui clima subtropical com inverno ameno (CROGE et al., 2016). Esta cultivar possui hastes vigorosas, eretas e sem espinhos, o que facilita os tratos culturais, como a poda, a condução e a colheita. É uma cultivar de baixa necessidade de frio, boa produtividade e indicada para o processamento (ANTUNES et al., 2014).

O baixo custo para implantação e manutenção dos pomares, a rusticidade das plantas e tolerância a pragas e doenças, torna o cultivo de amoreira preta uma opção para diversificação da agricultura familiar e cultivo agroecológico (ANTUNES et al., 2010; ANTUNES et al., 2014).

A amoreira preta é propagada pela estaquia de raízes e de ramos e por rebentos formados no campo a partir das plantas em produção (PIO e GONÇALVES, 2014). O problema destes métodos consiste na disseminação de pragas e doenças. Neste sentido a micropropagação apresenta como vantagens a produção de plantas sadias em grande número, com uniformidade e rapidez, preservando as características genéticas da planta matriz. Diversos estudos tem sido realizados para otimizar os protocolos de cultura de tecidos em espécies do gênero Rubus, procurando adequar a composição química dos meios de cultura (POOTHONG e REED, 2016), encontrar condições de iluminação mais adequadas (PASA et al., 2012), ajustar a concentração dos reguladores de crescimento (BUENO e BIASI, 2015), aumentar a eficiência de multiplicação com uso de biorreatores de imersão temporária (ARENCIBIA et al., 2013) e encontrar os melhores procedimentos para a conservação in vitro de germoplasma (SILVA et al., 2016).

Estudos recentes com o estabelecimento in vitro de amoreira preta 'Xavante', confirmam dificuldades nesta etapa relacionadas à contaminação e oxidação dos explantes, que pode ser reduzidas pela manutenção das plantas matrizes na ausência de luz (PELIZZA et al., 2016). Esta cultivar responde ao uso de citocininas para aumentar a multiplicação de brotações in vitro (PASA et al., 2012), mas uma definição mais precisa de formas de aplicação e concentração poderão melhorar a eficiência desta etapa, já que as cultivares de 
amoreira preta apresentam diferentes respostas de crescimento quando cultivadas no mesmo meio de cultura (OLIVEIRA et al., 2008).

O desenvolvimento de um sistema de enraizamento mais eficiente resulta em mudas com maior qualidade fisiológica e diminuição de perdas durante a fase de aclimatização (DAMIANI e SCHUCH, 2009), e um fator que pode influenciar no enraizamento in vitro de amoreira preta é a luminosidade. A restrição de luminosidade na fase inicial de brotação pode melhorar a formação de raízes (RADMANN et al., 2003). A substituição do agente geleificante por fibras ou materiais de suporte aerados ou porosos como a vermiculita ou as fibras de celulose, pode ser uma alternativa viável para favorecer o enraizamento e a formação de um sistema vascular normal, devido a aeração para respiração e do melhor aproveitamento de nutrientes pelas raízes (KOZAI e KUBOTA, 2001).

O presente trabalho teve por objetivos avaliar o efeito da 6-benzilaminopurina (BAP) na multiplicação de brotações e diferentes meios de cultura no enraizamento in vitro da amoreira preta cv. Xavante.

\section{MATERIAL E MÉTODOS}

Os explantes de amoreira preta cv. Xavante foram provenientes de plantas estabelecidas in vitro em fase de multiplicação em meio de cultura MS (MURASHIGE e SKOOG, 1962). As brotações foram multiplicadas em meio de cultura MS acrescido de 5 $\mu \mathrm{M}$ de BAP até a obtenção do número necessário para a instalação dos experimentos.

O meio de cultura utilizado em todos os experimentos foi o MS acrescido de 100 mg. $\mathrm{L}^{-1}$ de mio-inositol, 30 g. $\mathrm{L}^{-1}$ de sacarose e 6,5 g.L $\mathrm{L}^{-1}$ de ágar. $\mathrm{O}$ pH do meio de cultura foi ajustado para 5,8 antes da adição do ágar. Os frascos foram esterilizados em autoclave por 20 minutos, com temperatura de $120^{\circ} \mathrm{C}$ e pressão de 1 atm, mantidos em sala de crescimento, com temperatura de $25 \pm 2^{\circ} \mathrm{C}$ e o fotoperíodo de $16 \mathrm{~h}$ utilizando lâmpadas fluorescentes do tipo luz do dia de $40 \mathrm{~W}$. A intensidade luminosa média da sala de crescimento foi de $30 \mu \mathrm{mol} . \mathrm{m}^{-2} \cdot \mathrm{s}^{-1}$.

Para os experimentos, foram utilizados frascos com $67 \mathrm{~mm}$ de diâmetro e $87 \mathrm{~mm}$ de altura, fechados com tampa plástica e vedados com filme de PVC transparente, contendo 30 $\mathrm{mL}$ de meio de cultura, os quais receberam 5 explantes cada.

$\mathrm{O}$ experimento com diferentes concentrações de $\operatorname{BAP}(0,1$ e $5 \mu \mathrm{M})$ na multiplicação de brotações foi realizado por 3 subcultivos, sendo conduzido em delineamento experimental inteiramente casualizado, contendo 3 tratamentos com 5 repetições, sendo cada unidade experimental constituída por 1 frasco contendo 5 explantes de $4 \mathrm{~mm}$ de comprimento com 1 folha (para o primeiro subcultivo) e $10 \mathrm{~mm}$ de comprimento com 2 folhas (para o segundo e terceiro subcultivos). O primeiro, segundo e terceiro subcultivos foram mantidos por 97, 32 e 32 dias, respectivamente, em sala de crescimento.

As variáveis analisadas no experimento foram número de brotações, altura dos brotos, número de folhas por broto, número de raízes e a presença de calos. 
O experimento com estímulos de $\operatorname{BAP}(0,10$ e $20 \mu \mathrm{M})$ e transferência para outro meio de cultura sem reguladores foi realizado por 2 subcultivos, sendo conduzido em delineamento experimental inteiramente casualizado, contendo 3 tratamentos com 5 repetições, sendo cada unidade experimental constituída por 2 frascos contendo 5 explantes de $10 \mathrm{~mm}$ de comprimento com 2 folhas cada. Os explantes foram mantidos nos meios com BAP por 7 dias e após este estímulo inicial com BAP, os explantes foram transferidos para novos frascos contendo meio de cultura MS isento de regulador de crescimento e mantidos em sala de crescimento por mais 28 dias, totalizando 35 dias.

As variáveis analisadas foram número de brotações, altura dos brotos, número de folhas por broto, número de raízes e a presença de calos.

$\mathrm{O}$ experimento com diferentes meios de cultura no enraizamento in vitro de brotações foi conduzido em delineamento experimental inteiramente casualizado, contendo 4 tratamentos com 4 repetições, sendo cada unidade experimental constituída por 2 frascos contendo 5 explantes de $10 \mathrm{~mm}$ de comprimento com 2 folhas, mantido por 36 dias em sala de crescimento.

Os tratamentos foram os seguintes: $30 \mathrm{~mL}$ de meio de cultura MS semissólido por frasco com adição de 6,5 g.L $\mathrm{L}^{-1}$ de ágar; $30 \mathrm{~mL}$ de meio de cultura MS semissólido por frasco com adição de 6,5 g.L $\mathrm{L}^{-1}$ de ágar e 1 g.L $\mathrm{L}^{-1}$ de carvão ativado; $60 \mathrm{~mL}$ de meio de cultura MS líquido por frasco, com adição de $25 \%$ do volume do frasco com vermiculita média, para fixação das plantas; $30 \mathrm{~mL}$ de meio de cultura MS líquido por frasco com adição de 5 blocos de espuma fenólica com medidas 15 x 15 x $10 \mathrm{~mm}$ cada, contendo um orifício no centro de $5 \mathrm{~mm}$ de diâmetro e $5 \mathrm{~mm}$ de profundidade em cada bloco, para acomodação das plantas.

As variáveis analisadas foram número de raízes, comprimento de raízes e percentagem de enraizamento. Para os tratamentos com meio de cultura MS semissólido; meio de cultura MS semissólido com adição de carvão ativado; e meio de cultura MS líquido com adição de vermiculita média, foram avaliadas todas as plantas das unidades experimentais. Já para o tratamento com meio de cultura MS líquido com adição de blocos de espuma fenólica, foi avaliado um frasco contendo 5 plantas de cada unidade experimental. Isto ocorreu pela necessidade da destruição dos blocos de espuma fenólica para que as plantas pudessem ser avaliadas, juntamente com a necessidade de plantas para a sequência do experimento, na fase de aclimatização.

$\mathrm{O}$ experimento de aclimatização de plantas enraizadas in vitro foi conduzido em delineamento experimental inteiramente casualizado, contendo 4 tratamentos com 4 repetições, sendo cada unidade experimental constituída por 10 plantas para os tratamentos de meio MS semissólido, meio MS semissólido com carvão ativado e meio MS líquido com vermiculita média, e por 5 plantas para o tratamento de meio MS líquido com espuma fenólica, mantido por 46 dias em câmara de nebulização intermitente. 
As plantas foram colocadas em bandejas de isopor de 128 células contendo vermiculita média em câmara de nebulização intermitente, com controle automático de rega de 15 segundos a cada hora durante o dia e 15 segundo a cada 3 horas durante a noite.

As variáveis analisadas foram altura das plantas, número de folhas por planta, massa fresca e sobrevivência de plantas.

Os dados foram submetidos à análise de homogeneidade de variâncias pelo teste Bartlett, e quando não homogêneas foram transformados em $\sqrt{(x+1)}$ para satisfazer a condição. Após o teste de Bartlett, os dados foram submetidos à análise de variância pelo teste F, e, quando o efeito de tratamento foi significativo, realizou-se o teste de Tukey ao nível de 5\% de probabilidade. As análises estatísticas foram realizadas com o emprego do programa Assistat ${ }^{\circledR}$.

\section{RESULTADOS E DISCUSSÃO}

A adição de BAP ao meio de cultura estimulou a multiplicação da amoreira preta, sendo observado um aumento significativo no número de brotações em todos os subcultivos. As concentrações também diferiram, sendo que o uso de $5 \mu \mathrm{M}$ estimulou a emissão de aproximadamente o dobro de brotações do que $1 \mu \mathrm{M}$ (Tabela 1). Esta citocinina já apresentou efeito positivo na proliferação de brotações in vitro da amoreira preta 'Ébano' (VILLA et al., 2005).

Com a adição de $5 \mu \mathrm{M}$ de BAP obteve-se 7,12, 10,44 e 13,22 brotações por explante, no primeiro, segundo e terceiro subcultivo, respectivamente. Apesar dos explantes do primeiro subcultivo terem permanecido por mais tempo in vitro (97 dias), o número de brotações foi inferior ao segundo e terceiro subcultivos (32 dias cada), o que possivelmente se deve ao menor tamanho dos explantes utilizados. Desta forma, para o subcultivo da amoreira preta durante a fase de multiplicação, o uso de explantes com pelo menos 2 folhas é recomendável para a obtenção de maior número de brotações.

A concentração de $3,5 \mu \mathrm{M}$ de BAP também promoveu o aumento da taxa multiplicação para a cv. Xavante, mas com valores inferiores aos obtidos no presente trabalho, durante seis subcultivos $(2,7 ; 3,0 ; 6,8 ; 8,4 ; 7,4$; e 7,2) (OLIVEIRA et al., 2008). Estes autores observaram que a partir do quarto subcultivo, os explantes começaram a apresentar sintomas crescentes de hiperidricidade: $3 \%$ no quarto subcultivo, $16 \%$ no quinto subcultivo e $17 \%$ no sexto subcultivo. A hiperidricidade também foi observada no presente trabalho, mas em frequência e intensidade muito baixas. Esta é uma citocinina muito utilizada nos protocolos para a multiplicação de amora-preta e mesmo após oito subcultivos com 4,4 $\mu \mathrm{M}$ BAP, $0,5 \mu \mathrm{M}$ de ácido indolbutírico e $0,3 \mu \mathrm{M}$ de ácido giberélico, não foram observadas alterações genéticas em nível de ploidia ou no número de cromossomas das plantas micropropagadas (VUJOVIC et al., 2017). 
Tabela 1. Efeito de concentrações de BAP na multiplicação in vitro da amoreira-preta (Rubus sp.) cv. Xavante. Curitiba, PR. 2016.

\begin{tabular}{|c|c|c|c|c|c|}
\hline $\begin{array}{l}\text { BAP } \\
(\mu \mathrm{M})\end{array}$ & $\begin{array}{c}\text { Brotações } \\
\left(n^{o}\right)^{(1)}\end{array}$ & $\begin{array}{c}\text { Altura dos } \\
\text { brotos }(\mathrm{mm})\end{array}$ & $\begin{array}{l}\text { Folhas por } \\
\text { broto }\left(\mathrm{n}^{\circ}\right)\end{array}$ & Raízes (nº ${ }^{(1)}$ & $\begin{array}{c}\text { Presença de } \\
\text { calos }(\%)\end{array}$ \\
\hline \multicolumn{6}{|c|}{$1^{\circ}$ Subcultivo } \\
\hline 0 & $1,08 \mathrm{c}^{(2)}$ & $11,60 \quad \mathrm{a}^{(2)}$ & $6,32 \quad a b^{(2)}$ & $2,16 \quad b^{(2)}$ & 0 \\
\hline 1 & $3,76 \quad b$ & 13,19 a & $7,06 \quad \mathrm{~A}$ & 3,88 a & 100 \\
\hline 5 & 7,12 a & $6,68 \quad b$ & $4,62 \quad \mathrm{~B}$ & $2,72 \quad a b$ & 100 \\
\hline C.V. ${ }^{(3)}$ & 13,05 & 16,93 & 17,61 & 32,08 & - \\
\hline \multicolumn{6}{|c|}{$2^{\circ}$ Subcultivo } \\
\hline 0 & $1,04 \mathrm{c}$ & 16,26 a & $6,14 \quad \mathrm{~A}$ & $2,72 \quad a$ & $\begin{array}{ll}0 & b^{(2)}\end{array}$ \\
\hline 1 & $6,08 \quad b$ & $7,21 \quad b$ & $4,58 \quad \mathrm{~B}$ & $0,60 \quad b$ & 96 a \\
\hline 5 & $10,44 \quad \mathrm{a}$ & $5,47 \quad b$ & $3,43 \quad \mathrm{C}$ & $0,00 \quad b$ & $100 \quad \mathrm{a}$ \\
\hline C.V..$^{(3)}$ & 17,78 & 16,28 & 8,78 & 49,27 & 7,90 \\
\hline \multicolumn{6}{|c|}{$3^{\circ}$ Subcultivo } \\
\hline 0 & $1,04 \mathrm{c}$ & 15,56 a & $5,68 \quad \mathrm{~A}$ & $2,64 \quad \mathrm{a}$ & 0 \\
\hline 1 & $5,85 \quad b$ & $6,88 \quad b$ & $4,25 \quad \mathrm{~B}$ & $0,44 \quad b$ & 100 \\
\hline 5 & 13,22 a & $5,09 \quad \mathrm{c}$ & $3,23 \quad \mathrm{C}$ & $0,04 \quad b$ & 100 \\
\hline C.V. ${ }^{(3)}$ & 12,31 & 11,01 & 12,25 & 57,26 & - \\
\hline
\end{tabular}

${ }^{1}$ Os dados desta variável foram transformados em raiz quadrada de $(\mathrm{x}+1)$ para análise, mas as médias apresentadas são as originais. ${ }^{2}$ Médias seguidas por letras distintas na coluna diferem estatisticamente entre si a 5\% de probabilidade pelo teste de Tukey. ${ }^{3}$ Coeficiente de Variação (\%).

Foi observado um decréscimo na altura dos brotos nos três subcultivos com o aumento da concentração de BAP (Tabela 1). Constatou-se também um decréscimo no número de folhas com o aumento da concentração de BAP. Esta citocinina estimula a proliferação de brotações, mas estas são de tamanho reduzido, apresentando menor número de segmentos nodais e folhas (VILLA et al., 2005).

Houve um decréscimo no número de raízes no segundo e terceiro subcultivos com a adição de BAP, que se tornaram praticamente ausentes na concentração de $5 \mu \mathrm{M}$ (Tabela 1). Esta é uma resposta típica da permanência das brotações em presenta de citocininas, que inibem a diferenciação de raízes.

Não houve formação de calos na testemunha, enquanto em todos os tratamentos com BAP nos três cultivos foram observados calos. A formação destas massas celulares indiferenciadas na base dos explantes é uma resposta do estímulo a divisão celular promovido pela presença da citocinina no meio de cultura.

No experimento de estímulo de BAP na multiplicação de brotações foi observado um aumento significativo no número de brotações com o uso de BAP em ambos subcultivos, cujas concentrações diferiram apenas no primeiro subcultivo (Tabela 2). Com $20 \mu \mathrm{M}$ de BAP e transferência para outro meio sem reguladores, foi obtido 3,14 e 4,36 brotações por explante no primeiro e segundo subcultivo, respectivamente. Estas taxas de multiplicação 
foram inferiores as obtidas no experimento com a permanência do BAP durante toda a etapa da multiplicação.

Tabela 2. Efeito do estímulo de BAP por 7 dias na multiplicação in vitro da amoreira-preta (Rubus sp.) cv. Xavante. Curitiba, PR. 2016.

\begin{tabular}{|c|c|c|c|c|c|}
\hline $\begin{array}{l}\text { BAP } \\
(\mu \mathrm{M})\end{array}$ & $\begin{array}{c}\text { Brotações }\left(\mathrm{n}^{\mathbf{o}}\right) \\
(1)\end{array}$ & $\begin{array}{c}\text { Altura dos } \\
\text { brotos }(\mathrm{mm})\end{array}$ & $\begin{array}{l}\text { Folhas por } \\
\text { broto }\left(\mathrm{n}^{\circ}\right)\end{array}$ & Raízes (nº) & $\begin{array}{c}\text { Presença de } \\
\text { calos }(\%)\end{array}$ \\
\hline \multicolumn{6}{|c|}{$1^{\circ}$ Subcultivo } \\
\hline 0 & $1,06 \mathrm{c}^{(2)}$ & $12,36 \quad \mathrm{a}^{(2)}$ & $7,38 \mathrm{a}^{(2)}$ & $2,32 \quad \mathrm{a}^{(2)}$ & $4 b^{(2)}$ \\
\hline 10 & $1,82 \mathrm{~b}$ & $9,69 \quad b$ & $6,79 \quad a b$ & $1,38 \quad b$ & $16 \mathrm{~b}$ \\
\hline 20 & 3,14 a & $8,04 \quad b$ & $5,33 \quad b$ & $0,60 \mathrm{c}$ & $44 \mathrm{a}$ \\
\hline C.V. ${ }^{(3)}$ & 24,46 & 14,80 & 14,10 & 26,69 & 71,09 \\
\hline \multicolumn{6}{|c|}{$2^{\circ}$ Subcultivo } \\
\hline 0 & $1,08 \mathrm{~b}$ & $14,49 \quad \mathrm{a}$ & 5,97 a & $2,40 \quad a$ & $0 \quad b$ \\
\hline 10 & 4,62 a & $6,58 \quad b$ & $4,48 \quad b$ & $0,62 \quad b$ & 98 a \\
\hline 20 & 4,36 a & $6,63 \mathrm{~b}$ & $4,77 \quad b$ & $0,52 \quad b$ & $88 \mathrm{a}$ \\
\hline C.V. ${ }^{(3)}$ & 13,30 & 14,38 & 9,60 & 36,91 & 12,84 \\
\hline
\end{tabular}

Foi observado um decréscimo na altura dos brotos, no número de folhas e número de raízes nas concentrações de 10 e $20 \mu \mathrm{M}$ de BAP em ambos subcultivos.

O aumento do número de brotações com estímulo de BAP também foi obtido para Eucalyptus grandis com uma metodologia parecida, utilizando segmentos nodais tratados com três concentrações e BAP $(888,1776$ e $2664 \mu \mathrm{M})$ em três tempos de exposição $(1,2$ e 3 horas), sendo avaliadas após 21 dias (ANDRADE et al., 2006). Segundo estes autores, a concentração de BAP e o tempo de exposição apresentaram um aumento no número de brotações, sendo o tratamento com $888 \mu \mathrm{M}$ por 1 hora, o que proporcionou o maior número de brotações, tendo diferido apenas do tratamento com $888 \mu \mathrm{M}$ por 2 horas. Porém os autores ressaltaram que o aumento do número de brotações por tratamento, foi inversamente proporcional ao aumento da concentração e do tempo de exposição ao BAP.

No experimento de diferentes meios de cultura no enraizamento in vitro de brotações foi observado uma superioridade do meio MS líquido com vermiculita, com o qual obtevese 6,88 raízes por planta, seguido dos meios semissólidos com e sem adição de carvão ativado, os quais não diferiram estatisticamente, com 3,43 e 2,88 raízes por planta, respectivamente. O menor valor se deu com meio MS líquido com blocos de espuma fenólica, com apenas 1,35 raízes por planta, não diferindo estatisticamente do tratamento com meio MS semissólido sem adição de carvão ativado (Tabela 3 e Figura 1). O aumento do número de raízes com o uso de vermiculita, também foi constatado com o mirtileiro in vitro (DAMIANI e SCHUCH, 2009) e ex vitro, sendo o melhor substrato em comparação com outros constituídos por Plantmax ${ }^{\circledR}$ e serragem curtida de pinus (PELIZZA et al., 2012). 
Tabela 3. Efeito do meio de cultura no enraizamento in vitro de brotações e na aclimatização de plantas da amoreira-preta (Rubus sp.) cv. Xavante. Curitiba, PR. 2016.

\begin{tabular}{cccccccc}
\hline $\begin{array}{c}\text { Meio de } \\
\text { cultura }\end{array}$ & NR $\left(\mathrm{n}^{\mathrm{o}}\right)$ & $\mathrm{CR}(\mathrm{mm})$ & $\mathrm{E}(\%)$ & $\mathrm{AP}(\mathrm{mm})$ & $\mathrm{NF}\left(\mathrm{n}^{\mathrm{o}}\right)$ & $\mathrm{MF}(\mathrm{mg})$ & $\mathrm{S}(\%)$ \\
\hline $\mathrm{SS}$ & $2,88 \mathrm{bc}^{(1)}$ & $22,81 \mathrm{a}^{(1)}$ & $95 \mathrm{a}^{(1)}$ & $23,68 \mathrm{~b}^{(1)}$ & $7,40 \mathrm{~b}^{(1)}$ & $341 \mathrm{ab}^{(1)}$ & 100 \\
\hline $\mathrm{SSCA}$ & $3,43 \mathrm{~b}$ & $25,14 \mathrm{a}$ & $100 \mathrm{a}$ & $25,75 \mathrm{~b}$ & $7,58 \mathrm{~b}$ & $262 \mathrm{~b}$ & 100 \\
\hline $\mathrm{LV}$ & $6,88 \mathrm{a}$ & $4,14 \mathrm{~b}$ & $100 \mathrm{a}$ & $31,58 \mathrm{a}$ & $9,35 \mathrm{a}$ & $410 \mathrm{a}$ & 100 \\
\hline $\mathrm{LEF}$ & $1,35 \mathrm{c}$ & $2,08 \mathrm{~b}$ & $60 \mathrm{~b}$ & $14,80 \mathrm{c}$ & $8,05 \mathrm{~b}$ & $357 \mathrm{ab}$ & 100 \\
\hline $\mathrm{C} . \mathrm{V} \cdot{ }^{(2)}$ & 20,47 & 16,98 & 9,76 & 8,81 & 6,29 & 18,56 & - \\
\hline
\end{tabular}

Meio MS semissólido (SS); Meio MS semissólido com carvão ativado (SSCA); Meio MS líquido com vermiculita (LV); Meio MS líquido com espuma fenólica (LEF); Número de raízes (NR); Comprimento das raízes (CR); Enraizamento (E); Altura de plantas (AP); Número de folhas (NF); Massa fresca (MF); Sobrevivência de plantas (S). ${ }^{1}$ Médias seguidas por letras distintas na coluna diferem estatisticamente entre si a 5\% de probabilidade pelo teste de Tukey. ${ }^{2}$ Coeficiente de Variação (\%).

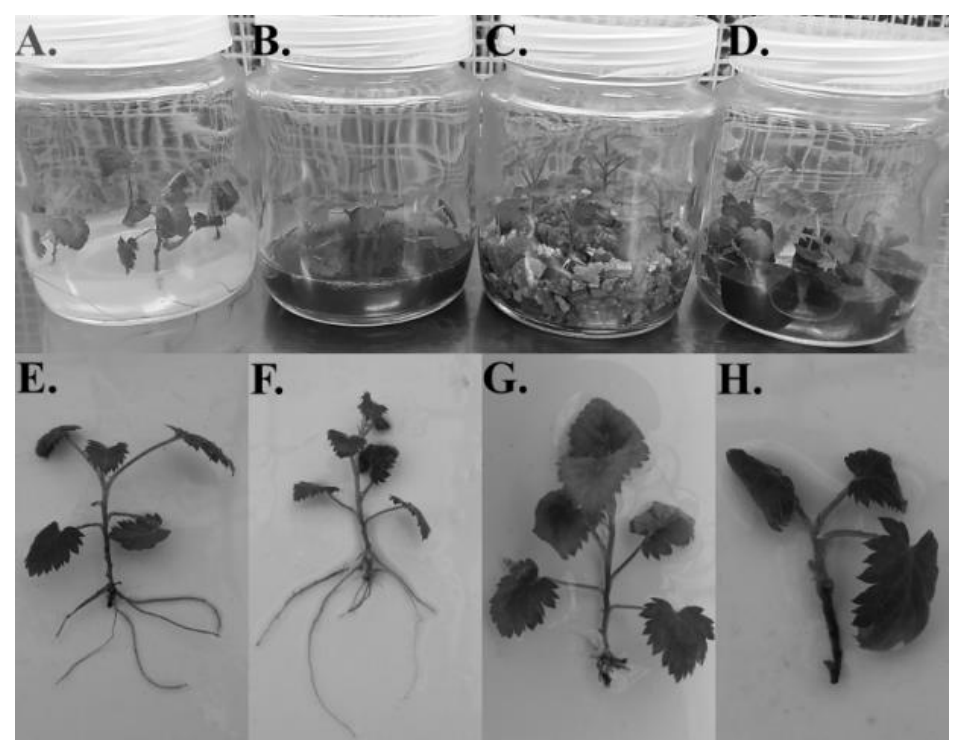

Figura 1. Plantas de amoreira-preta cv. Xavante em meios MS semissólido (A, E); MS semissólido com carvão ativado (B, F); MS líquido com vermiculita (C, G); e MS líquido com espuma fenólica (D, H), após 36 dias em sala de crescimento para enraizamento in vitro. Curitiba, PR, 2016.

Já para o comprimento das raízes, os meios MS semissólidos com e sem a adição de carvão ativado obtiveram melhores resultados, não diferenciando estatisticamente entre si, com 25,14 e 22,81 mm respectivamente, quando comparados aos meios MS líquidos com vermiculita e espuma fenólica, que também não diferenciando estatisticamente entre si, com 4,14 e 2,08 mm respectivamente. A adição de carvão ativado ao meio de cultura em concentrações de 10 e 20 g.L. $\mathrm{L}^{-1}$ foi prejudicial para a porcentagem de enraizamento, número e comprimento das raízes para a mesma cultivar de amoreira preta (LEITZKE et al., 2009). No presente trabalho isto não foi observado, possivelmente porque a concentração utilizada foi de apenas 1 g.L - $^{-1}$, não ocasionando nenhuma diferença entre os meios com e sem carvão. 
O meio MS líquido com espuma fenólica prejudicou a percentagem de enraizamento, que foi de apenas $60 \%$, enquanto os demais meios não diferiram entre si, apresentando elevadas porcentagens de enraizamento.

Todas as plantas aclimatizadas sobreviveram, inclusive aquelas que não tinham enraizado in vitro dos tratamentos com meio semissólido e meio com espuma fenólica, confirmando a facilidade para aclimatização da amoreira preta (AUGUSTO et al., 2006; PELIZZA et al., 2013).

O crescimento das plantas aclimatizadas provenientes do meio MS líquido com vermiculita foi superior aos demais tratamentos em relação à altura das plantas e número de folhas. Já para a variável massa fresca, o meio MS líquido com vermiculita foi superior ao MS semissólido com adição de carvão ativado e não diferiu dos demais tratamentos (Tabela 3 e Figura 2).

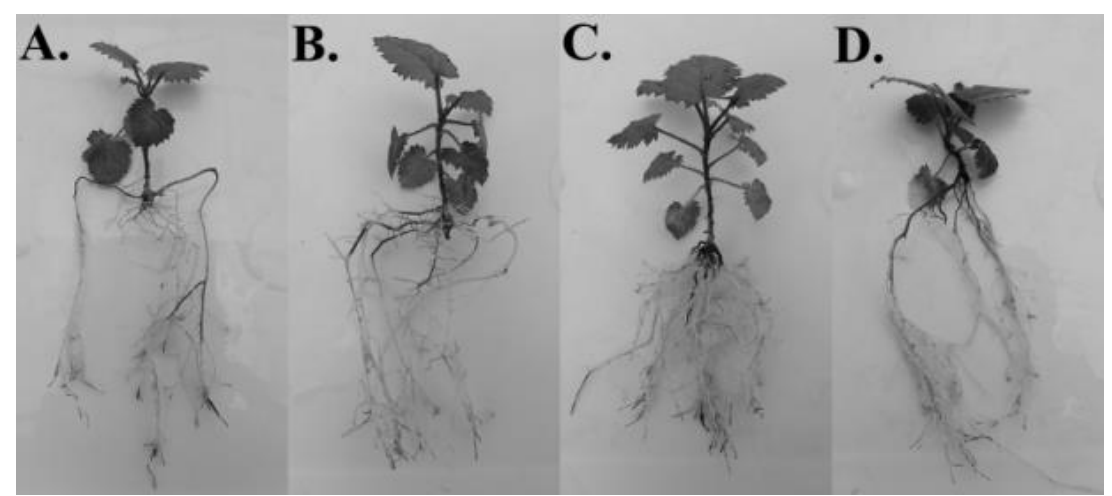

Figura 2. Plantas de amoreira-preta cv. Xavante advindas de meios MS semissólido (A); MS semissólido com carvão ativado (B); MS líquido com vermiculita (C); e MS líquido com espuma fenólica (D), após 46 dias em câmara de nebulização intermitente para aclimatização. Curitiba, PR. 2016.

As plantas originadas do meio MS líquido com vermiculita por possuírem raízes mais curtas (Figura 1G) apresentam maior facilidade de transplante para as bandejas do que aquelas com raízes longas. O maior desenvolvimento das plantas provenientes deste tratamento (Figura 2C) também é um indicativo de que elas deverão formar mudas mais vigorosas para o plantio.

\section{CONCLUSÃO}

A adição de BAP na concentração $5 \mu \mathrm{M}$ ao meio de cultura MS é eficaz na multiplicação de brotações da amoreira preta cv. Xavante.

Para o enraizamento in vitro da amoreira preta cv. Xavante recomenda-se o meio de cultura MS líquido com vermiculita.

As plantas de amoreira preta cv. Xavante apresentam facilidade para o enraizamento e aclimatização. 


\section{REFERÊNCIAS BIBLIOGRÁFICAS}

ANDRADE, W. F.; ALMEIDA, M.; GONÇALVES, A. N. Multiplicação in vitro de Eucalyptus grandis sob estímulo com benzilaminopurina. Pesquisa Agropecuária Brasileira, Brasília, v. 41, n. 12, p.1715-1719, 2006. Disponível em: <http://seer.sct.embrapa.br/index.php/pab/article/view/7337>. Acesso em: 18 jan. 2018.

ANTUNES, L. E. C.; GONÇALVES, E. D.; TREVISAN, R. Fenologia e produção de cultivares de amoreira-preta em sistema agroecológico. Ciência Rural, Santa Maria, v. 40, n. 9, p.1929-1933, 2010. Disponível em: <http://dx.doi.org/10.1590/S010384782010000900012>. Acesso em: 18 jan. 2018.

ANTUNES, L. E. C.; PEREIRA, I. S.; PICOLOTTO, L.; VIGNOLO, G. K.; GONÇALVES, M. A. Produção de amoreira-preta no Brasil. Revista Brasileira de Fruticultura, Jaboticabal, v. 36, n. 1, p.100-111, 2014. Disponível em: <http://dx.doi.org/10.1590/0100-2945-450/13>. Acesso em: 18 jan. 2018.

ARENCIBIA, A. D.; VERGARA, C.; QUIROZ, K.; CARRASCO, B.; GARCÍAGONZALEZ, R. Establishment of photomixotrophic cultures for raspberry micropropagation in Temporary Immersion Bioreactors (TIBs). Scientia Horticulturae, Amsterdan, v. 160, p.49-53, 2013. Disponível em: <https://doi.org/10.1016/j.scienta.2013.05.010>. Acesso em: 18 jan. 2018.

AUGUSTO, C. S. S.; BIASI, L. A.; TELlES, C. A. Enraizamento e aclimatização de plantas micropropagadas de amoreira-preta cv. Brazos. Revista Brasileira de Fruticultura, Jaboticabal, v. 28, n. 3, p.473-476, 2006. Disponível em: <http://dx.doi.org/10.1590/S010029452006000300029>. Acesso em: 18 jan. 2018.

BUENO, P. M. C.; BIASI, L. A. Micropropagation of greenberry (Rubus erythroclados). Acta Horticulturae, Leuven, n. 1083, p.383-389, 2015. Disponível em: <http://dx.doi.org/10.17660/ActaHortic.2015.1083.48>. Acesso em: 18 jan. 2018.

CROGE, C. P.; CUQUEL, F. L.; BIASI, L. A.; BONA, C. M. de. Performance of blackberry cultivars in Cerro Azul-PR. Revista Brasileira de Fruticultura, Jaboticabal, v. 38, n. 3 (e-141), p.1-8, 2016. Disponível em: <http://dx.doi.org/10.1590/010029452016141>. Acesso em: 18 jan. 2018.

CURI, P. N.; PIO, R.; MOURA, P. H. A.; TADEU, M. H.; NOGUEIRA, P. V.; PASQUAL, M. Produção de amora-preta e amora-vermelha em Lavras-MG. Ciência Rural, Santa Maria, v. 45, n. 8, p.1368-1374, 2015. Disponível em: <http://dx.doi.org/10.1590/01038478cr20131572>. Acesso em: 18 jan. 2018.

DAMIANI, C. R.; SCHUCH, M. W. Diferentes substratos e ambientes no enraizamento in vitro de mirtilo. Ciência Rural, Santa Maria, v. 39, n. 2, p.563-566, 2009. Disponível em: <http://dx.doi.org/10.1590/S0103-84782009000200040>. Acesso em: 18 jan. 2018.

FERREIRA, D. S.; ROSSO, V. V.; MERCADANTE, A. Z. Compostos bioativos presentes em amora-preta (Rubus spp.). Revista Brasileira de Fruticultura, Jaboticabal, v. 32, n. 3, 
p.664-674, 2010. Disponível em: <http://dx.doi.org/10.1590/S0100-29452010005000110>. Acesso em: 18 jan. 2018.

GUEDES, M. N. S.; MARO, L. A. C.; ABREU, C. M. P. DE; PIO, R.; PATTO, L. S. Composição química, compostos bioativos e dissimilaridade genética entre cultivares de amoreira (Rubus spp.) cultivadas no Sul de Minas Gerais. Revista Brasileira de Fruticultura, Jaboticabal, v. 36, n. 1, p.206-2013, 2014. Disponível em: <http://dx.doi.org/10.1590/0100-2945-230/13>. Acesso em: 18 jan. 2018.

KOZAI, T; KUBOTA, C. Developing a photoautotrophic micropropagation system for woody plants. Journal of Plant Research, Tokyo, v. 114, n. 4, p.525-537, 2001. Disponível em: 〈https://doi.org/10.1007/PL00014020〉. Acesso em: 18 jan. 2018.

LEITZKE, L. N.; DAMIANI, C. R.; SCHUCH, M. W. Multiplicação e enraizamento in vitro de amoreira-preta 'Xavante': Efeito da concentração de sais, do tipo de explante e de carvão ativado no meio de cultura. Ciência e Agrotecnologia, Lavras, v. 33, Edição Especial, p.1959-1966, 2009. Disponível em: <http://dx.doi.org/10.1590/S141370542009000700045>. Acesso em: 18 jan. 2018.

MURASHIGE, T.; SKOOG, F. A revised medium for rapid growth and bio assays with tobacco tissue cultures. Physiologia Plantarum, Copenhagen, v. 15, n. 3, p.473-497, 1962. Disponível em: <http://dx.doi.org/10.1111/j.1399-3054.1962.tb08052.x>. Acesso em: 18 jan. 2018.

OLIVEIRA, R. P.; NINO, A. F. P.; FERREIRA, L. V. Potencial de multiplicação in vitro de cultivares de amoreira-preta. Revista Brasileira de Fruticultura, Jaboticabal, v. 30, n. 3, p.585-589, 2008. Disponível em: 〈http://dx.doi.org/10.1590/S0100-29452008000300004>. Acesso em: 18 jan. 2018.

PASA, M. S.; CARVALHO, G. L.; SCHUCH, M. W.; SCHMITZ, J. D.; TORCHELSEN, M. M.; NICKEL, G. K., SOMMER, L. R.; LIMA, T. S.; CAMARGO, S. S. Qualidade de luz e fitorreguladores na multiplicação e enraizamento in vitro da amoreira-preta 'Xavante'. Ciência Rural, Santa Maria, v. 42, n. 8, p.1392-1396, 2012. Disponível em: <http://dx.doi.org/10.1590/S0103-84782012000800010>. Acesso em: 05 jun. 2018.

PELIZZA, T. R.; MUNIZ, J.; CAMARGO, P.; KRETZSCHMAR, A. A.; RUFATO, L. Enraizamento ex vitro e aclimatização de plântulas micropropagadas de amoreira-preta 'Xavante'. Revista Brasileira de Fruticultura, Jaboticabal, v. 35, n. 1, p.333-337, 2013. Disponível em: <http://dx.doi.org/10.1590/S0100-29452013000100039>. Acesso em: 18 jan. 2018.

PELIZZA, T. R.; NASCIMENTO, D. C.; AFFONSO, L. B.; CAMARGO, S. S.; CARRA, B.; SCHUCH, M. W. Enraizamento de plântulas de mirtileiro em condição ex vitro com diferentes substratos. Revista Brasileira de Fruticultura, Jaboticabal, v. 34, n. 1, p.255261, 2012. Disponível em: <http://dx.doi.org/10.1590/S0100-29452012000100034>. Acesso em: 18 jan. 2018. 
PELIZZA, T. R.; SILVEIRA, F. N.; RIBEIRO, R. S.; MACHADO, B. D.; RUFATTO, L.; KRETZSCHMAR, A. A. In vitro establishment of blackberry (Rubus sp.) cultivar 'Xavante'. Ciência Rural, Santa Maria, v. 46, n. 9, p.1542-1545, 2016. Disponível em: <http://dx.doi.org/10.1590/0103-8478cr20140988>. Acesso em: 18 jan. 2018.

PIO, R.; GONÇALVES, E. D. Cultivo da amoreira-preta. In: PIO, R. Cultivo de fruteiras de clima temperado em regiões subtropicais e tropicais. Lavras: Ed. UFLA, 2014. p. 186-221.

POOTHONG, S.; REED, B. M. Optimizing shoot culture media for Rubus germplasm: the effects of NH4+, NO3-, and total nitrogen. In Vitro Cellular \& Developmental Biology Plant, New York, v. 52, n. 3, p.265-275, 2016. Disponível em: <http://dx.doi.org/10.1007/s11627-016-9750-0>. Acesso em: 05 jun. 2018.

RADMANN, E. B.; GONÇALVEZ, E. D.; FORTES, G. R. L. Concentrações de ácido indolbutírico e períodos de escuro, no enraizamento "in vitro" de amoreira-preta (Rubus spp.), cv. Ébano. Revista Brasileira de Fruticultura, Jaboticabal, v. 25, n. 1, p.124-126, 2003. Disponível em: <http://dx.doi.org/10.1590/S0100-29452003000100035>. Acesso em: 18 jan. 2018.

SILVA, N. D. G.; DUTRA, L. F.; BIANCHI, V. J.; SOMMER, L. R.; VARGAS, D. P.; PETERS, J. A. Conservação in vitro de amoreira-preta: Crescimento lento. Plant Cell Culture \& Micropropagation, Lavras, v. 12, n. 1, p.7-12, 2016. Disponível em: <http://177.105.2.193/ojs/index.php/PlantCellCultureMicropropagation/article/view/82>. Acesso em: 18 jan. 2018.

VILLA, F.; ARAÚJO, A. G.; PIO, L. A. S.; PASQUAL, M. Multiplicação in vitro da Amoreira-preta 'Ébano' em diferentes concentrações de meio MS e BAP. Ciência e Agrotecnologia, Lavras, v. 29, n. 3, p.582-589, 2005. Disponível em: <http://dx.doi.org/10.1590/S1413-70542005000300011>. Acesso em: 18 jan. 2018.

VUJOVIC, T.; RUZIC, D.; CEROVIC, E.; LEPOSAVIC, A.; KARAKLAJIC-STAJIC, Z.; MITROVIC, O.; ZURAWICZ, E. An assessment of the genetic integrity of micropropagated raspberry and blackberry plants. Scientia Horticulturae, Amsterdan, v. 225, p.454-461, 2017. Disponível em: 〈https://doi.org/10.1016/j.scienta.2017.07.020〉. Acesso em: 23 abr. 2018. 